\title{
Development of a controlled release formulation based on SLN and NLC for topical clotrimazole delivery
}

\author{
E.B. Souto ${ }^{\mathrm{a}, \mathrm{b}}$, S.A. Wissing ${ }^{\mathrm{a}}$, C.M. Barbosa ${ }^{\mathrm{b}}$, R.H. Müller ${ }^{\mathrm{a}, *}$ \\ a Department of Pharmaceutics, Biopharmaceutics and Biotechnology, \\ Free University of Berlin, Kelchstr. 31, D-12169 Berlin, Germany \\ ${ }^{\mathrm{b}}$ Department of Pharmaceutical Technology, Faculty of Pharmacy, Oporto University, \\ Rua Aníbal Cunha, 164 P-4050-047 Porto, Portugal
}

Received 1 August 2003; received in revised form 19 February 2004; accepted 21 February 2004

\begin{abstract}
Solid lipid nanoparticles (SLN) and nanostructured lipid carriers (NLC) are colloidal carrier systems providing controlled release profiles for many substances. Clotrimazole-loaded SLN and NLC were prepared by the hot high pressure homogenization technique in order to evaluate the physical stability of these particles, as well as the entrapment efficiency of this lipophilic drug and its in vitro release profile. The particle size was analyzed by PCS and LD showing that the particles remained in their colloidal state during 3 months of storage at 4,20 and $40{ }^{\circ} \mathrm{C}$. For all tested formulations the entrapment efficiency was higher than $50 \%$. The obtained results also demonstrate the use of these lipid nanoparticles as modified release formulations for lipophilic drugs over a period of $10 \mathrm{~h}$.
\end{abstract}

(C) 2004 Elsevier B.V. All rights reserved.

Keywords: Solid lipid nanoparticles; Nanostructured lipid carriers; Clotrimazole; Franz diffusion cells

\section{Introduction}

Solid lipid nanoparticles $\left(\mathrm{SLN}^{\mathrm{TM}}\right)$ were developed at the beginning of the 1990s as an alternative carrier system to the existing traditional carriers, such as emulsions, liposomes and polymeric nanoparticles (Müller and Lucks, 1996). The major advantage of SLN is the possibility of production on large industrial scale (Müller et al., 2000a). However, depending on the drug some potential problems can occur, such as drug leakage during storage and insufficient total drug load. To overcome the limitations of SLN, nanos-

\footnotetext{
* Corresponding author. Tel.: +49-30-83850678; fax: +49-30-83850616.

E-mail address: mpharma@zedat.fu-berlin.de (R.H. Müller).
}

tructured lipid carriers (NLC ${ }^{\mathrm{TM}}$ ) have been developed (Müller et al., 2000b,c). The later consist of a solid lipid matrix with a high content of liquid lipid (Radke, 2003).

Both SLN and NLC possess a number of features advantageous for the topical route of application (Müller et al., 1995, 2000d, 2002; Mehnert and Mäder, 2001). These carriers are composed of physiological and biodegradable lipids of low systemic toxicity and also low cytotoxicity (Müller et al., 1997). Most of the used lipids have an approved status or are excipients used in commercially available topical cosmetic or pharmaceutical preparations. The small size of the lipid particles ensures close contact to the stratum corneum and can increase the amount of the drug penetrating into the mucosa or skin. Due to their solid 
lipid matrix, controlled release from these carriers is possible. This becomes an important tool when it is necessary to supply the drug over a prolonged period of time and to reduce systemic absorption, and when the drug is irritating at high concentrations. As a result of film formation after topical application occlusive properties were also reported (Müller et al., 2002; Wissing and Müller, 2001, 2002a; Wissing et al., 2001).

Clotrimazole was used as a highly lipophilic model drug in the present study. The aim of this work was focused on drug release and occlusive properties of clotrimazole-loaded SLN and NLC. In order to assess the in vitro release pattern of the drug from these carriers, the recommended Franz diffusion cells were used.

\section{Materials}

Dynasan ${ }^{\circledR} 116$ (glyceryl tripalmitate) was purchased from Contensio Chemicals GmbH (Witten, Germany), tyloxapol was provided by Sigma Aldrich (Deisenhofen, Germany) and clotrimazole and Miglyol ${ }^{\circledR} 812$ were obtained from Caelo, Germany. The materials were used as received. Water was used in double-distilled quality.

\section{Methods}

\subsection{Production of $S L N$ and NLC}

Glyceryl tripalmitate (Dynasan ${ }^{\circledR} 116$ ) SLN were produced by the hot homogenization technique with a high pressure homogenizer APV Micron Lab 40 (APV Deutschland GmbH, Lübeck, Germany). The lipid was heated up to $90{ }^{\circ} \mathrm{C}$ and $5 \%$ of clotrimazole (related to the lipid matrix) was added to the melted Dynasan ${ }^{\circledR} 116$. The hot lipid phase was dispersed in the hot surfactant solution $\left(90^{\circ} \mathrm{C}\right)$, using an Ultra-Turrax T25 (Jankle \& Kunkel GmbH and Co KG, Staufen, Germany) at $8000 \mathrm{rpm}$ for $1 \mathrm{~min}$. The obtained pre-emulsion was then homogenized at $90{ }^{\circ} \mathrm{C}$ by high pressure homogenization applying three homogenization cycles at 500 bar.

Glyceryl tripalmitate (Dynasan ${ }^{\circledR} 116$ ) NLC were prepared in exactly the same manner as the SLN dispersions, only partially replacing $30 \%$ of the solid lipid matrix by $\mathrm{Miglyol}^{\circledR} 812$ (caprylic/capric triglycerides).

\subsection{Particle sizing and drug entrapment efficiency}

Particle size was analyzed by photon correlation spectroscopy (PCS) with a Zetasizer 4 (Malvern Instruments, UK) and by laser diffractometry (LD), using a Coulter ${ }^{\circledR}$ LS 230 (Coulter Electronics, Germany). PCS yields the mean particle size and the polydispersity index $(\mathrm{PI})$ as a measure of the width of the distribution. The LD data were evaluated using the diameter $90 \%\left(d_{90 \%}\right)$, which means that $90 \%$ (volume distribution) of the measured particles are below this value.

The percentage of incorporated clotrimazole (entrapment efficiency) was determined by spectrophotometric determination at $243 \mathrm{~nm}$ using an Uvikon 940 (Kontron Instruments, Eching, Germany), after centrifugation of the aqueous dispersion. The amount of free drug was detected in the supernatant and the amount of incorporated drug was determined as a result of the initial drug minus the free drug. The entrapment efficiency could be calculated by the following equation:

$\mathrm{EE}(\%)=\left(\frac{W_{\text {initial drug }}-W_{\text {free drug }}}{W_{\text {initial drug }}}\right) \times 100$

where " $W_{\text {initial drug" }}$ " is the mass of initial drug used for the assay and the " $W_{\text {free drug }}$ " is the mass of free drug detected in the supernatant after centrifugation of the aqueous dispersion.

\subsection{Release studies}

The release studies were performed with static Franz diffusion cells $(0.9 \mathrm{~cm}$ in diameter, Crown Scientific, Sommerville, USA). The diffusion cells were thermoregulated with a water jacket at $32{ }^{\circ} \mathrm{C}$. Cellulose nitrate $(0.1 \mu \mathrm{m}$ pore diameter, Sartorius, Göttingen, Germany) membrane filters were mounted to Franz diffusion cells. Acetate buffer ( $\mathrm{pH}$ 6.0) with $35 \%$ of dioxan was used as receptor fluid. $100 \mu l$ of SLN or NLC aqueous dispersion (containing 1\% of clotrimazole) was applied to the donor compartment. Samples $(250 \mu \mathrm{l})$ were collected over $24 \mathrm{~h}$ and analyzed by spectrophotometric determination at $243 \mathrm{~nm}$ 
using an Uvikon 940 (Kontron Instruments). The release studies were performed in triplicate.

\subsection{Occlusion test}

The in vitro occlusion test was adapted by de Vringer (1992). Beakers $(100 \mathrm{ml})$ were filled with $50 \mathrm{ml}$ of water, covered with filter paper (cellulose acetate filter, $90 \mathrm{~mm}$, Schleicher, Germany; cutoff size: 4-7 $\mu \mathrm{m}$ ) and sealed. $200 \mathrm{mg}$ of sample was spread evenly with a spatula on the filter surface $\left(18.8 \mathrm{~cm}^{2}\right)$, leading to an applied amount of $10.6 \mathrm{mg} / \mathrm{cm}^{2}$. A visible film formation on top of the filter paper was observed during the experiment. The samples were stored at $32{ }^{\circ} \mathrm{C}$ (skin temperature) and $50-55 \%$ r.h. for $48 \mathrm{~h}$. The samples were weighed after 6, 24 and $48 \mathrm{~h}$, giving the water loss due to evaporation at each time (water flux through the filter paper). Beakers covered with filter paper but without applied sample served as reference values. Every experiment was performed in triplicate $(n=3)$. The occlusion factor $F$ was calculated according to the following equation:

$$
F=\left(\frac{A-B}{A}\right) \times 100
$$

where $A$ is the water loss without sample (reference) and $B$ is the water loss with sample. An occlusion factor of 0 means no occlusive effect compared to the reference and 100 is the maximum occlusion factor.

\section{Results and discussion}

\subsection{Characterization of the investigated formulations}

Three different types of lipid particles were produced by hot high pressure homogenization. The composition of the investigated formulations is shown in
Table 1. After production the aqueous dispersions were stored at three different temperatures $\left(4,20\right.$ and $\left.40^{\circ} \mathrm{C}\right)$ and their particle size was measured during 3 months.

Fig. 1 shows the LD mean diameters $\left(d_{90 \%}\right)$ after 1, 60 and 90 days of storage and Fig. 2 shows the PCS mean diameters and the polydispersity index (PI) after 90 days at 4,20 and $40^{\circ} \mathrm{C}$. For all formulations the $d_{90 \%}$ measured by LD was below $0.5 \mu \mathrm{m}$ at room temperature. The batches stored at $4{ }^{\circ} \mathrm{C}$ show higher particle sizes, but also in the nanometer range. The PCS measurements show that the particle size remains lower than $300 \mathrm{~nm}, 3$ months after production. It could also be observed that the particle size increased with the increase of lipid concentration.

\subsection{Entrapment efficiency}

SLN are prepared from solid lipids or blends of solid lipids. After hot high pressure homogenization the lipid recrystallizes in higher energy modifications, i.e. $\alpha$ - and $\beta$-forms (Westesen et al., 1993). During storage, these polymorphic forms can transform to a more ordered modification $(\beta)$, which is characterized by a lower energy modification and a higher degree of crystallinity. These parameters are strongly correlated with drug incorporation (Bunjes et al., 1996). Drug expulsion in SLN can occur when the lipid matrix transforms from high energy modifications, characterized by the presence of many imperfections, to the $\beta$-modification forming a perfect crystal with no room for guest molecules. This phenomenon is even more pronounced when high purity lipids are used. To overcome this problem, NLC have been developed. The lipid matrix of these particles is constituted by solid lipids and liquid lipids, which can be mixed in such a combination that the particle solidifies upon cooling but does not recrystallize and remains in the amorphous state. A second type of NLC is formed when the lipid molecules are chemically very different, resulting in a structure with many imperfections to

Table 1

Composition of the investigated SLN and NLC formulations (\%,w/w)

\begin{tabular}{lllll}
\hline Formulation & Dynasan ${ }^{\circledR} 116$ & Tyloxapol & Clotrimazole & Miglyol ${ }^{\circledR} 812$ \\
\hline A (SLN) & 9.5 & 3 & 0.5 & - \\
B (SLN) & 19 & 5 & 1 & - \\
C (NLC) & 13.5 & 5 & 1 & 5.5 \\
\hline
\end{tabular}




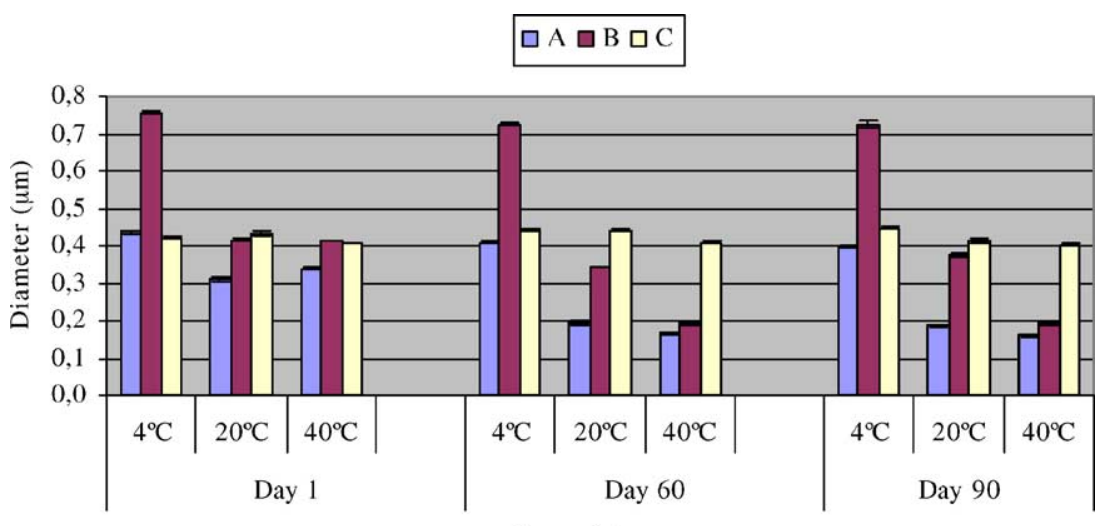

Days of storage

Fig. 1. Particle size $(\mu \mathrm{m})$ of SLN (A and B) and NLC (C) formulations measured by LD $\left(d_{90 \%}\right)$ after 1,60 and 90 days of storage at 4 , 20 and $40^{\circ} \mathrm{C}$.

accommodate the drug and thus higher loading capacity (Fig. 3).

The percentage of incorporated drug in the lipid matrix (entrapment efficiency) was evaluated over a period of 21 days. The results are shown in Fig. 4. Incorporation of clotrimazole led to high entrapment efficiency, probably because of their lipophilic character. NLC formulation (C) is responsible for a higher entrapment efficiency in comparison to both SLN formulations (A and B). This result is due to the binary mixture of liquid and solid lipids, resulting in only a very weak crystallization (Jenning et al., 2000a,b).For SLN formulations, the entrapment efficiency is lower for the sample with lower lipid concentration. It has to be noticed that during the cooling process after homogenization, the lipid solidifies and the drug is distributed into the shell of the particles, if the concentration of the drug in the melted lipid is well below its saturation solubility. As a result, SLN show a drug-enriched shell model (Formulation A, Fig. 5). A drug-enriched core model (Formulation B, Fig. 5) is formed when the drug in the melted lipid is closed to its saturation solubility. The cooling process leads to supersaturation of the drug and subsequently to drug crystallization prior to lipid crystallization (Wissing and Müller, 2002b).

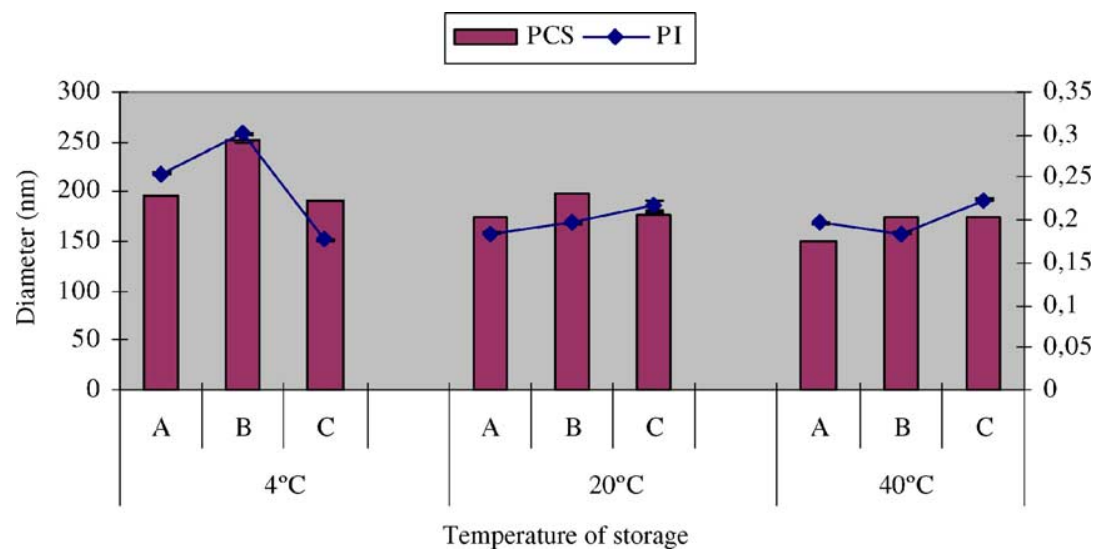

Fig. 2. Diameter (nm) and polydispersity index (PI) of SLN (A and B) and NLC (C) formulations measured by PCS after 90 days of storage at 4,20 and $40^{\circ} \mathrm{C}$. 


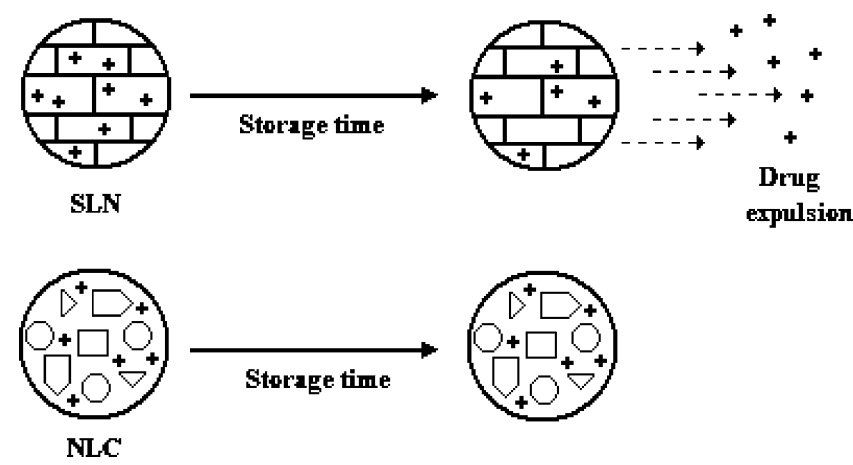

Fig. 3. Formation of a perfect lipid crystal in SLN and a crystal lattice with many imperfections in NLC.

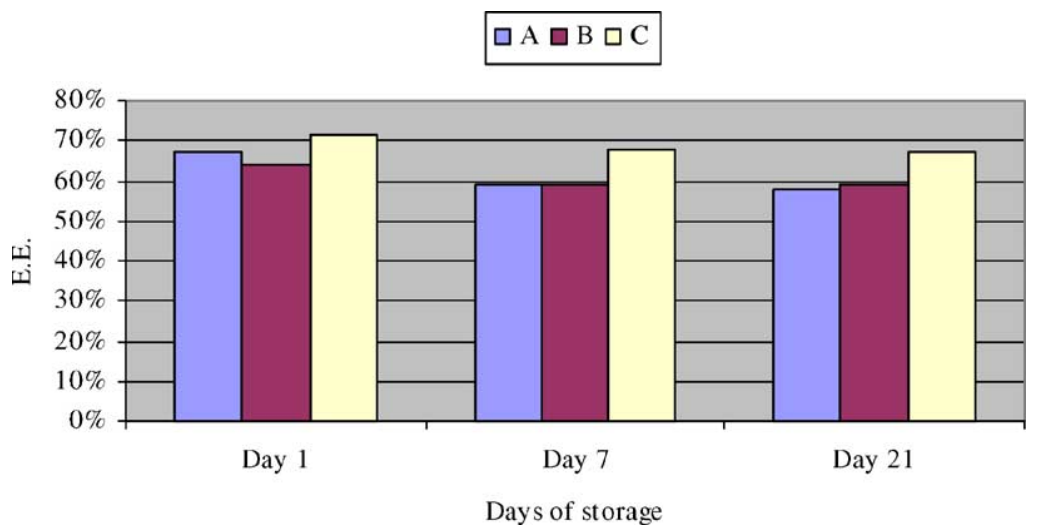

Fig. 4. Entrapment efficiency (EE) of clotrimazole in different SLN (A and B) and NLC (C) formulations, calculated after 1, 7 and 21 days of storage at room temperature.

\subsection{In vitro release studies}

In order to evaluate the controlled release potential of the investigated formulations, the diffusion of

\section{SLN with $10 \%$ of lipid}

(Formulation A)

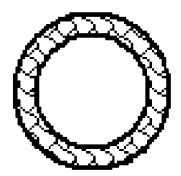

Drug-enriched shell model

\section{SLN with $20 \%$ of lipid}

(Formulation B)

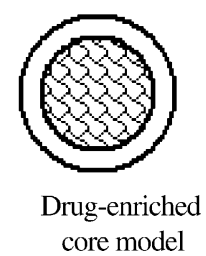

Fig. 5. Models of incorporation of active compound into SLN. Lipid core with compound-enriched outer shell (left), drug-enriched core with lipid shell (right). clotrimazole from the lipid particles was investigated over $24 \mathrm{~h}$. Each sample was analyzed in triplicate. The results are shown in Fig. 6.

The release rate of clotrimazole depends on the total concentration of drug in the formulation. Clotrimazole is released more quickly when using lower concentration because of the drug-enriched shell model proposed for these particles (Formulation A). Due to the large drug loading in Formulation B, the degree of diffusion can be decreased. On the contrary, due to the liquid structure of NLC, the formulation C shows a faster release.

\subsection{Occlusion test}

As reported above, lipid nanoparticles show adhesive properties, i.e. they tend to adhere to cells and surfaces, and due to the film formation of the 


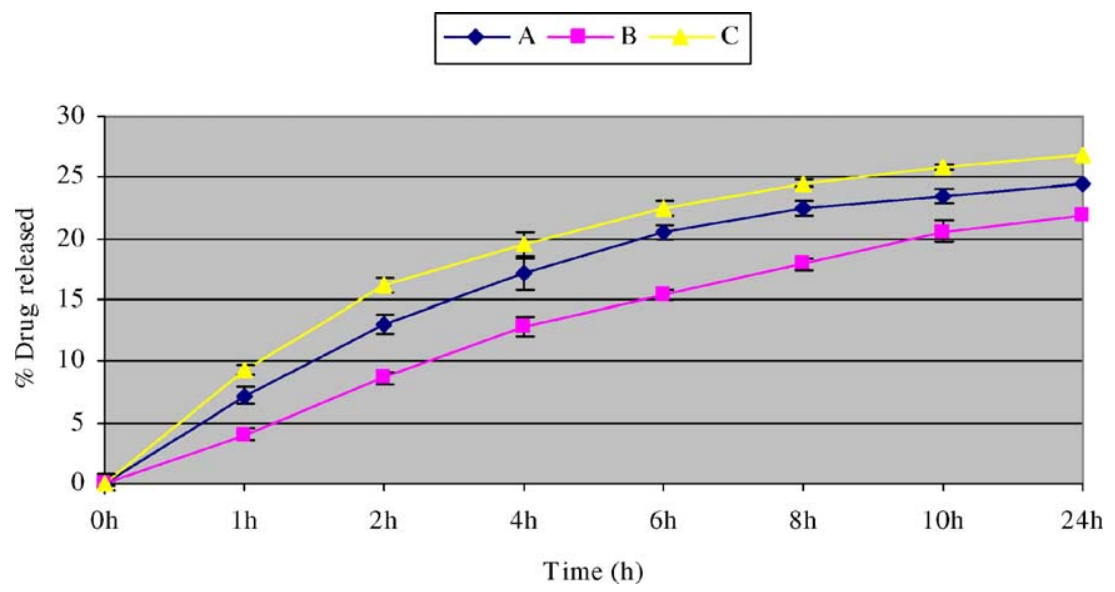

Fig. 6. Release profile of clotrimazole of SLN (A and B) and NLC (C) formulations stored at room temperature.

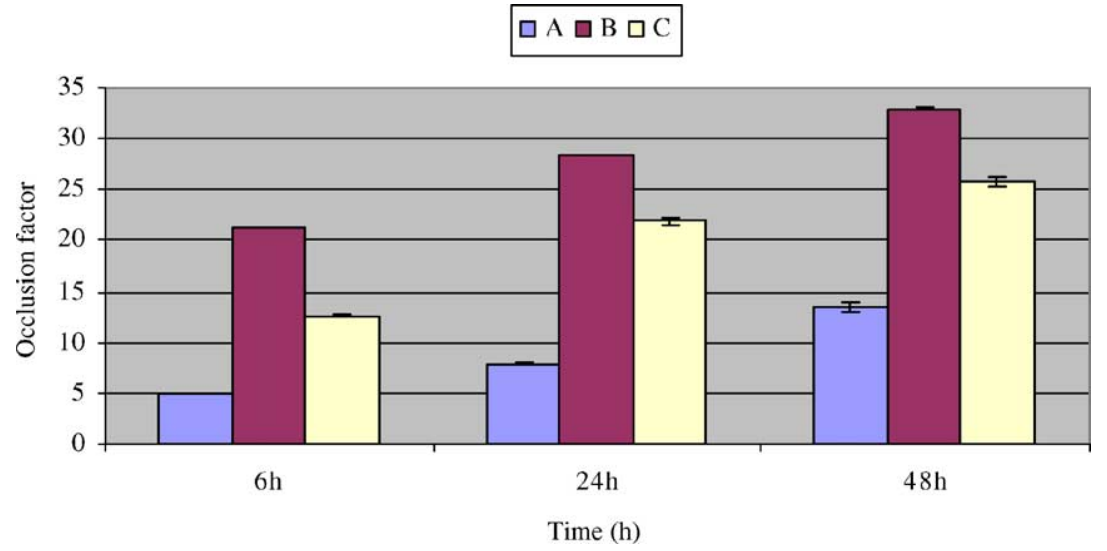

Fig. 7. Occlusion factors of the investigated SLN (A and B) and NLC (C) formulations.

nanoparticles on the skin, SLN possess occlusive properties (Wissing et al., 2001; de Vringer, 1992; Jenning et al., 1999; Müller and Dingler, 1998). It could be stated that the drug released from a conventional formulation is accumulated in the stratum corneum over the time course. This phenomenon offers the possibility to enhance the drug's therapeutic index (Jenning et al., 1999).

As reported by Wissing et al. (2001), the occlusion factor is dependent upon the sample volume, particle size and crystallinity; therefore, samples of $200 \mathrm{mg}$ were applied to the membrane of Franz cells. The results of the occlusion test are shown in Fig. 7.

According to Wissing et al. (2001), the occlusion factor depends strongly on the lipid concentration and the particle size of SLN. Our results show a lower F for SLN containing lower lipid concentration (Formulation A). For the same lipid concentration (Formulations B and C) a lower occlusivity can be detected for NLC than for SLN. This result is due to the solid state of the lipid matrix of SLN, which disables the evaporation of water.

\section{Conclusions}

This study indicates that both SLN and NLC are potential carriers systems for topical delivery of clotrimazole. After 3 months of storage at different temperatures the mean diameters of SLN and NLC remain 
practically the same $(<1 \mu \mathrm{m})$, which emphasizes the physical stability of these lipid particles.

The entrapment efficiency and the drug release profile depend on the concentration and the lipid mixture employed. NLC show a higher entrapment efficiency due to their liquid parts. In agreement to this results NLC also show a faster release profile in comparison to SLN with the same lipid concentration. The release rate decreases for SLN with a higher lipid concentration, which is explained by the physical morphology of the lipid particles.

Finally, it can also be concluded that SLN show a higher occlusive capacity in comparison to NLC with the same lipid content.

\section{References}

Bunjes, H., Westesen, K., Koch, M.H.J., 1996. Crystallization tendency and polymorphic transitions in triglyceride nanoparticles. Int. J. Pharm. 129, 159-173.

Jenning, V., Hildebrand, G.E., Gysler, A., Müller, R.H., SchäferKorting, M., Gohla, S., 1999. Solid lipid nanoparticles (SLN) for topical application: occlusive properties. Proc. Int. Symp. Control. Release Biact. Mater. 26, 405-406.

Jenning, V., Thünemann, A.F., Gohla, S.H., 2000a. Characterisation of a novel solid lipid nanoparticle carrier system based on binary mixtures of liquid and solid lipids. Int. J. Pharm. 199, 167-177.

Jenning, V., Mäder, K., Gohla, S.H., 2000b. Solid lipid nanoparticles (SLN) based on binary mixtures of liquid and solid lipids: a ${ }^{1}$ H NMR study. Int. J. Pharm. 205, 15-21.

Mehnert, W., Mäder, K., 2001. Solid lipid nanoparticlesproduction, characterization and applications. Adv. Drug Deliv. Rev. 47, 165-196.

Müller, R.H., Dingler, A., 1998. The next generation after the liposomes: solid lipid nanoparticles (SLN, Lipopearls) as dermal carriers in cosmetics. Eurocosmetics 7/8, 19-26.

Müller, R.H., Lucks, J.S., 1996. Arzneistoffträger aus festen Lipidteilchen-Feste Lipid Nanosphären (SLN). EP 0605497.

Müller, R.H., Mehnert, W., Lucks, J.S., Schwarz, C., zur Mühlen, A., Weyhers, H., Freitas, C., Rühl, D., 1995. Solid lipid nanoparticles (SLN) — an alternative colloidal carrier system for controlled drug delivery. Eur. J. Pharm. Biopharm. 41, 62-69.

Müller, R.H., Rühl, D., Runge, S., Schulze-Forster, K., Mehnert, W., 1997. Cytotoxicity of solid lipid nanoparticles as a function of the lipid matrix and the surfactant. Pharm. Res. 14, 458462.

Müller, R.H., Lippacher, A., Gohla, S., 2000a. Solid lipid nanoparticles (SLN) as a carrier system for the controlled release of drugs. In: Wise, D. (Ed.), Handbook of Pharmaceutical Controlled Release Technology. Marcel Dekker, New York, USA, pp. 377-392.

Müller, R.H., et al., 2000b. Solid-liquid (semi-solid) lipid particles and method of producing highly concentrated lipid particle dispersions. German Patent Application 199,45,203.2.

Müller, R.M., Mäder, K., Lippacher, A., Jenning, V., 2000c. Festflüssige (halbfeste) Lipidpartikel und Verfahren zur Herstellung hochkonzentrierter Lipidpartikel-dispersionen. PCT/EP00/ 04565 .

Müller, R.H., Mäder, K., Gohla, S., 2000d. Solid lipid nanoparticles (SLN) for controlled drug delivery-a review of the state of art. Eur. J. Pharm. Biopharm. 50, 161-177.

Müller, R.H., Radtke, M., Wissing, S.A., 2002. Solid lipid nanoparticles (SLN) and nanostructured lipid carriers (NLC) in cosmetic and dermatological preparations. Adv. Drug Deliv. Rev. 54, 131-155.

Radke, M., 2003. Grundlegende Untersuchungen zur Arzneistoffinkorporation-freisetzung und Struktur von SLN and NLC. Ph.D. Thesis, Freie Universität Berlin.

de Vringer, T., 1992. Topical preparation containing a suspension of solid lipid particles. European Patent No. 91200664.

Westesen, K., Siekmann, B., Hoch, M.H.J., 1993. Investigations on the physical state of lipid nanoparticles by synchrotron radiation X-ray diffraction. Int. J. Pharm. 93, 189-199.

Wissing, S.A., Müller, R.H., 2001. A novel sunscreen system based on tocopherol acetate incorporated into solid lipid nanoparticles. Int. J. Cosmet. Sci. 23, 233-243.

Wissing, S.A., Müller, R.H., 2002a. The influence of the crystallinity of lipid nanoparticles on their occlusive properties. Int. J. Pharm. 242, 377-379.

Wissing, S.A., Müller, R.H., 2002b. Solid lipid nanoparticles as carrier for sunscreens: in vitro release and in vivo skin penetration. J. Control. Release 81, 225-233.

Wissing, S.A., Lippacher, A., Müller, R.H., 2001. Investigations on the occlusive properties of solid lipid nanoparticles (SLN). J. Cosmet. Sci. 52, 313-323. 